
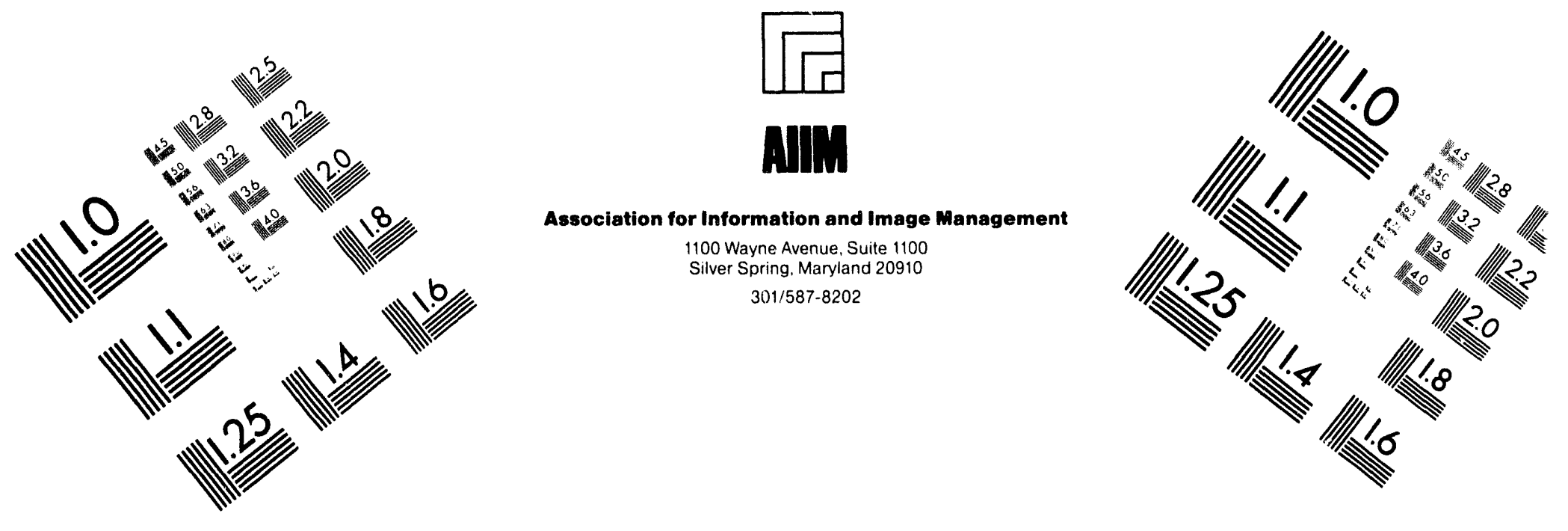

Centimeter

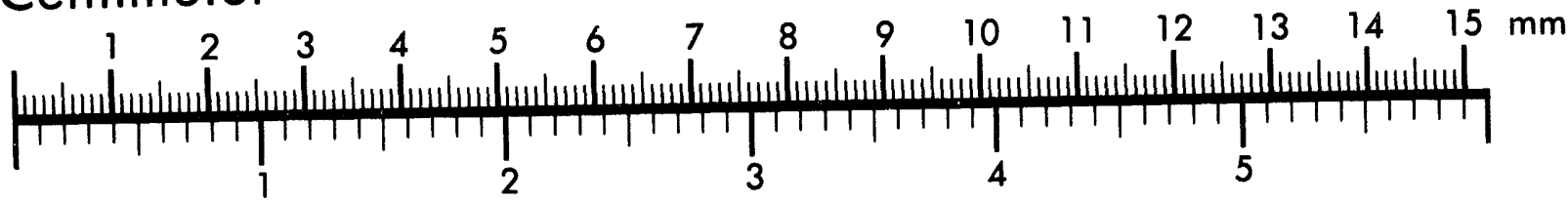
Inches
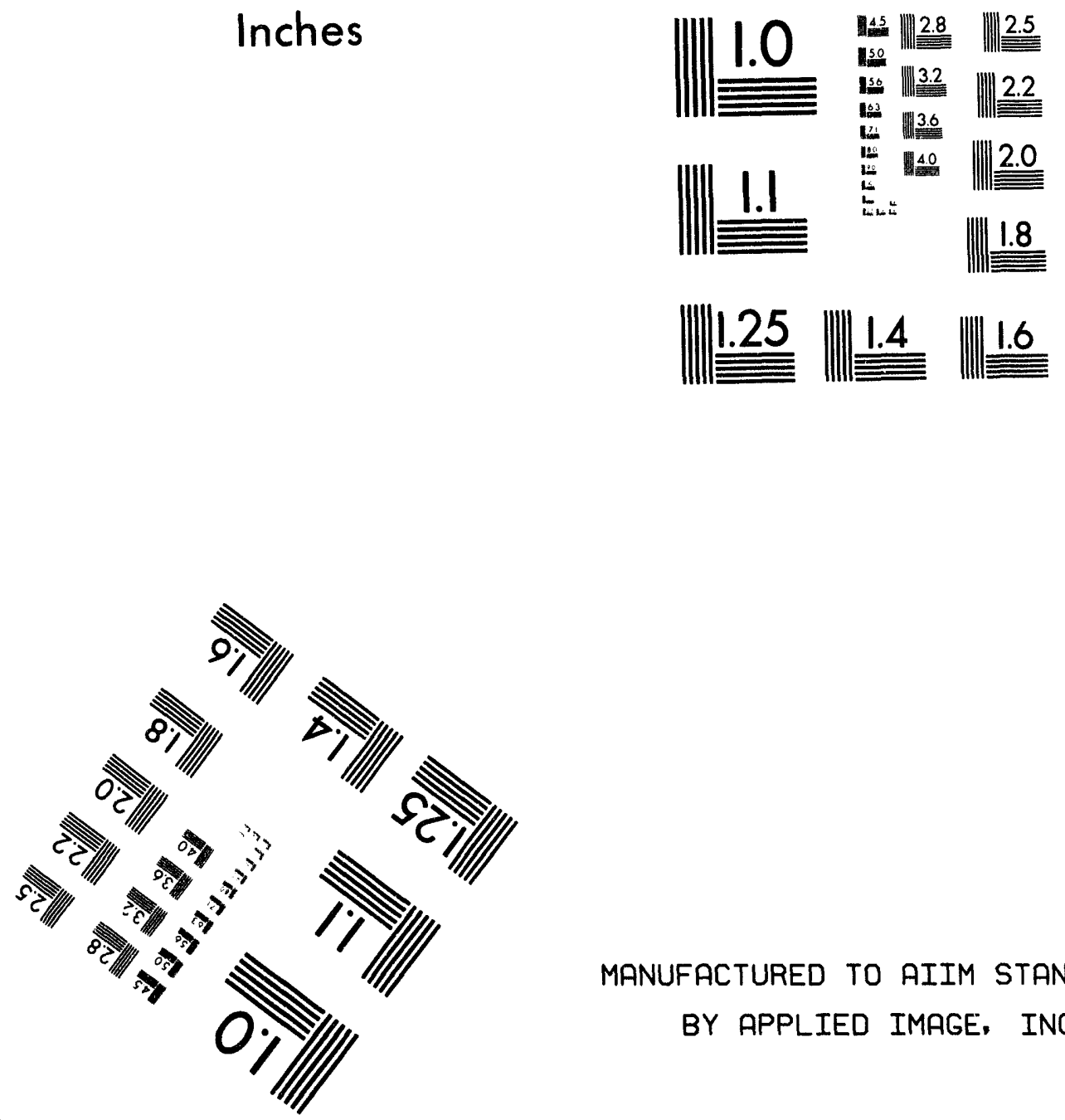

MANUFACTURED TO AIIM STANDARDS BY APPLIED IMAGE, INC.

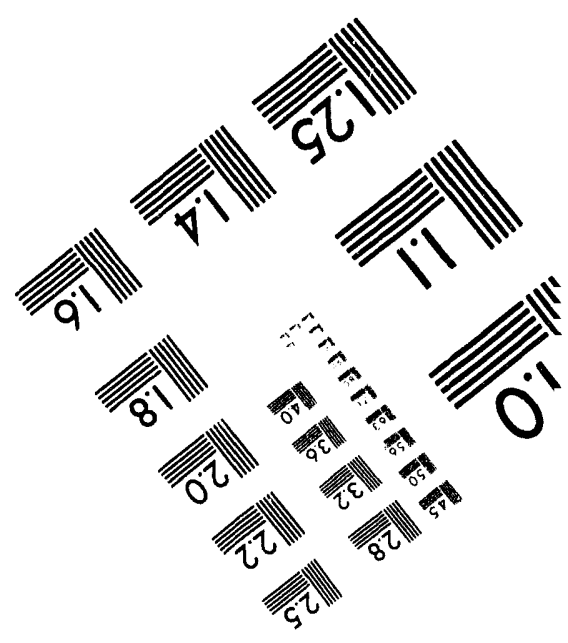



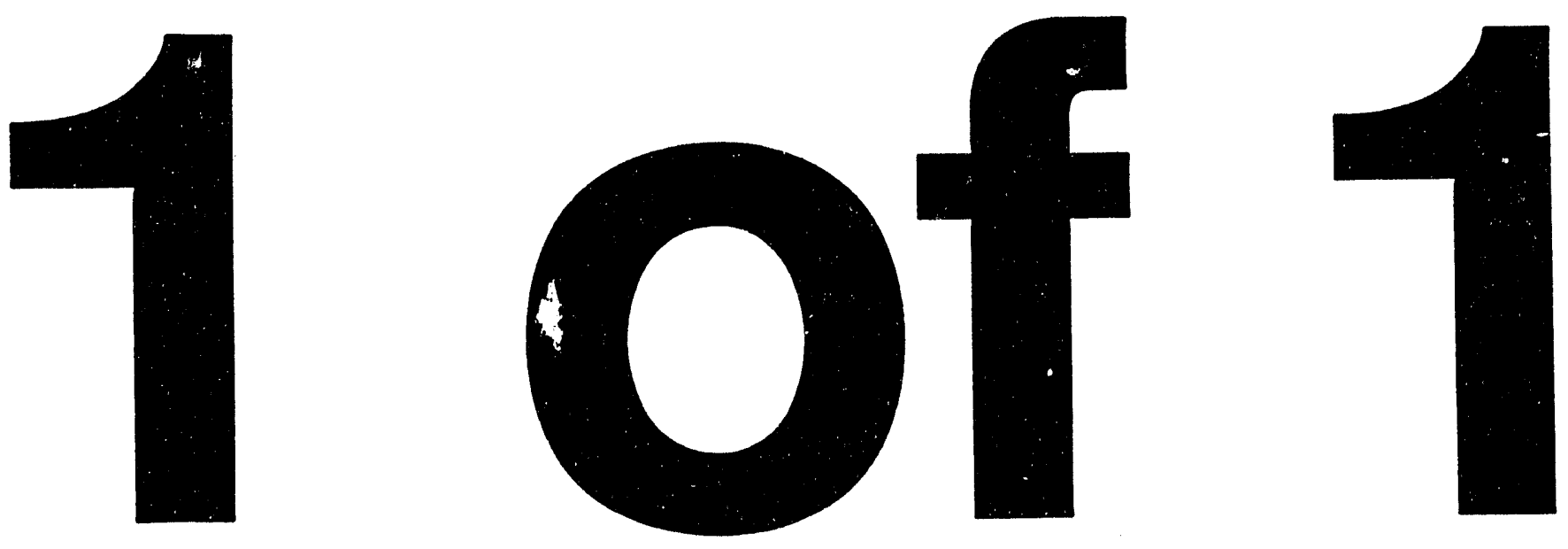
PREPARED FOR THE U.S. DEPARTMENT OF ENERGY, UNDER CONTRACT DE-AC02-76-CHO-3073

PPPL-3003

PPPL-3003

UC-426

\section{EFFECTS OF TURBULENT FLUCTUATIONS ON DENSITY MEASUREMENTS WITH MICROWAVE REFLECTOMETRY IN TOKAMAKS}

BY

E. MAZZUCATO AND R. NAZIKIAN

AUGUST, 1994
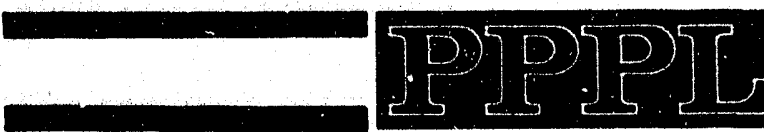

paINCETON

plazma pHYzice

laEomatopY

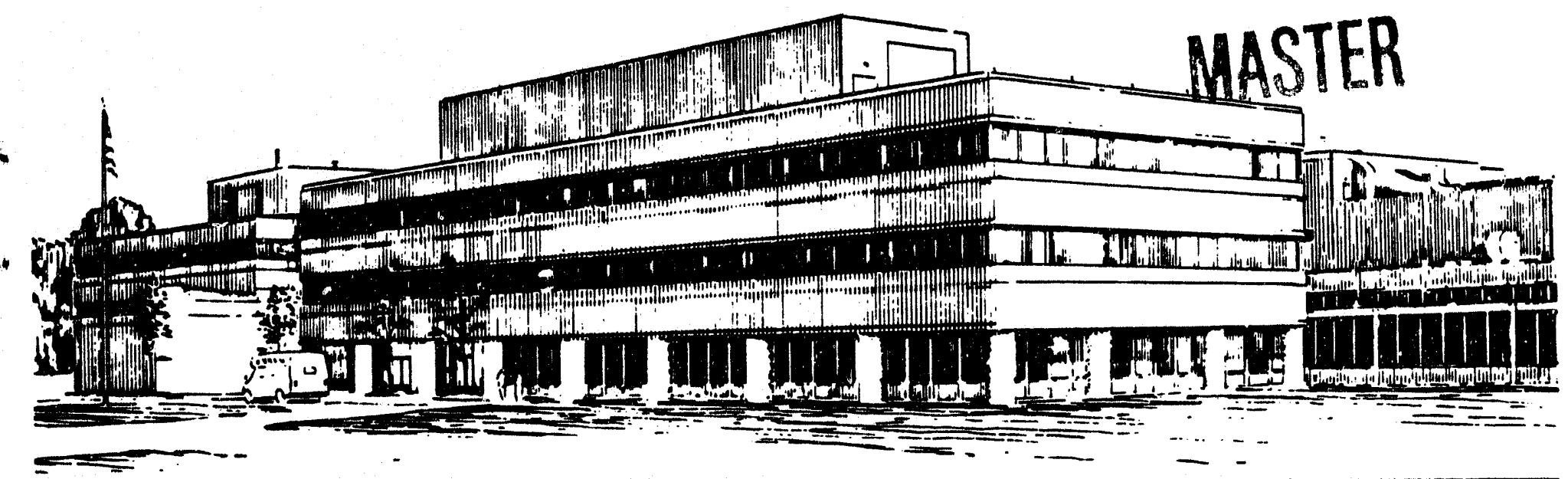

\section{PRINCETON UNIVERSITY, PRINCETON, NEW JERSEY}




\section{NOTICE}

This report was prepared as an account of work sponsored by an agency of the United States Government. Neither the United States Government nor any agency thereof, nor any of their employees, makes any warranty, express or implied, or assumes any legal liability or responsibility for the accuracy, completeness, or usefulness of any information, apparatus, product, or process disclosed, or represents that its use would not infringe privately owned rights. Reference herein to any specific commercial produce, process, or service by trade name, trademark, manufacturer, or otherwise, does not necessarily constitute or imply its endorsement, recommendation, or favoring by the United States Government or any agency thereof. The views and opinions of authors expressed herein do not necessarily state or reflect those of the United States Government or any agency thereof.

\section{NOTICE}

This report has been reproduced from the best available copy.

Available in paper copy and microfiche.

Number of pages in this report: 15

DOE and DOE contractors can obtain copies of this report from:

Office of Scientific and Technical Information

P.O. Box 62

Oak Ridge, TN 37831 ;

(615) $576-8401$.

This report is publicly available from the:

National Technical Information Service

Department of Commerce

5285 Port Royal Road

Springfield, Virginia 22161

(703) $487-4650$ 


\title{
Effects of turbulent fluctuations on density measurements with microwave reflectometry in tokamaks
}

\author{
E. Mazzucato and R. Nazikian \\ Princeton Plasma Physics Laboratory, P.O. Box 451, Princeton, New Jersey 08543
}

The short-scale turbulence of tokamak plasmas has deleterious effects on the measurement of plasma density with microwave reflectometry. Density fluctuations may lead to large amplitude and phase modulations of the reflected wave which can impair the measurement of the wave group delay, and hence the determination of the plasma density. The role played by different types of turbulent fluctuations and the limitations imposed on microwave reflectometry are discussed in this paper.

\section{INTRODUCTION}

Plasma measurements in a fusion reactor will be a dauntingly difficult task since they will require penetration not only into the containment vessel and the magnetic field coils, as in present tokamaks, but also into the tritium breeding blanket and the radiation shield. Inevitably, only the most simple diagnostics will be feasible in such a hostile environment. One method which has the potential for being one of these diagnostic tools is microwave reflectometry. In this method, originally proposed more than a decade ago ${ }^{1,2}$, the plasma density is inferred from the position of a cutoff which reflects an electromagnetic wave. For practical reasons, the latter is usually launched into the plasma from the equatorial midplane, perpendicular to the magnetic surfaces. The main advantage of this technique is the modest requirement of plasma accessibility, which is that required by a small waveguide, and the possibility of conveying the received wave to a remote location. Several variations of the original concept have been used with various degree of success, including the latest versions of Ref. 3 and 4.

The presence of turbulent fluctuations may severely increase the difficulty of obtaining the position of the wave cutoff, and hence the plasma density, from phase measurements. Indeed, the first application of microwave reflectometry in tokamaks ${ }^{5}$ was not for the measurement of the average plasma density, but rather for the study of density fluctuations. The difficulty stems from the fact that, while the effects of density fluctuations which vary only in the radial direction, i.e., parallel to the direction of wave propagation, can be compensated for by averaging over the fluctuations, those fluctuations varying along the tokamak poloidal direction, i.e., perpendicularly to the direction of wave propagation, make the interpretation of 
reflectometry measurements very difficult, if not impossible. In this paper, we discuss the different roles played by the radial and poloidal structure of turbulent fluctuations which, in spite of their fundamental importance, are still not well understood by most reflectometry practitioners.

\section{FLUCTUATIONS}

For simplicity, we will consider the case of practical interest where in the absence of plasma fluctuations the wave trajectory remains close to the tokamak equatorial plane, and propagates in an almost radial direction. Within the approximation of geometric optics, the phase $\phi$ of the reflected wave, apart from an additive constant, is

$$
\phi=2 k_{0} \int_{0}^{r_{c}} \varepsilon^{1 / 2} d r
$$

where $k_{\mathrm{o}}$ is the vacuum wave numbur, $\varepsilon$ is the plasma permittivity, $r$ is the radial coordinate, $r>0$ is the plasma region, and $r_{c}$ is the position of the reflecting layer.

\section{A. Radial fluctuations}

We consider first the simplest case where the average electron density $n_{e}(r)$ is perturbed by one dimensional random density fluctuations $\tilde{n}_{e}(r)$. The phase $\phi$ of the reflected wave is still given by Eq. (1), with $\varepsilon$ containing a fluctuating term. Previously 6 , we have found that this expression agrees with the value derived from the Born approximation of the wave equation when the radial scale length of $\tilde{n}_{e}$ is a few times $(2+3)$ larger than the free space wavelength. Nevertheless, once this condition is satisfied, the validity of Eq. (1) is not limited to the case of small fluctuations.

Let $\Gamma_{\varepsilon}$ and $\Gamma_{\phi}$ be the power spectra of the fluctuating parts of $\varepsilon$ and $\phi$ (considered as a function of $r_{c}$ ), respectively, so that

$$
\begin{aligned}
\left\langle\tilde{\varepsilon}\left(r_{1}\right) \tilde{\varepsilon}\left(r_{2}\right)\right\rangle & =\int \Gamma_{\varepsilon}\left(k_{r}\right) e^{i k_{r}\left(r_{2}-r_{1}\right)} d k_{r}, \\
\left\langle\tilde{\phi}\left(r_{c 1}\right) \tilde{\phi}\left(r_{C 2}\right)\right\rangle & =\int \Gamma_{\phi}\left(k_{r}\right) e^{i k_{r}\left(r_{C 2}-r_{C 1}\right) d k_{r},}
\end{aligned}
$$

where the brackets $\langle$ represent ensemble averages. For small density fluctuations, Eq. (1) gives

$$
\tilde{\phi} \approx k_{0} \int_{0}^{r_{c}} \tilde{\varepsilon} /\langle\varepsilon\rangle^{1 / 2} d r
$$


which is valid when $L_{\varepsilon} \equiv|d\langle\varepsilon\rangle / d r|_{r=r_{c}}^{-1} \neq 0$, the case of practical interest for avoiding wave tunnelling. Since the major contribution to this integral comes from a narrow region near the reflecting layer where $\langle\varepsilon\rangle \approx 0$, we can approximate the denominator of the integrand in Eq. (3) with $\left[\left(r_{c}-r\right) / L_{\varepsilon}\right]^{1 / 2}$. By substituting Eq. (3) into the second of Eqs. (2), we obtain 7

$$
\Gamma_{\phi}\left(k_{r}\right) \approx 2 \pi \frac{k_{0}^{2} L_{\varepsilon}}{k_{r}}\left[C^{2}(w)+S^{2}(w)\right] \Gamma_{\varepsilon}\left(k_{r}\right),
$$

where $C(w)$ and $S(w)$ are the Fresnel integrals 8 , and $w=\left(2 k_{r} L_{\varepsilon} / \pi\right)^{1 / 2}$. For $w<<1$, the term within square brackets is $\approx w^{2}$, while for $w>>1$ it is $\approx 1 / 2$. By using the density dependence of the plasma permittivity we can express Eq. (4) in terms of the spectral density $\Gamma_{n}\left(k_{r}\right)$ of the relative fluctuation $\tilde{n}_{e} / n_{e}$. We obtain

$$
\Gamma_{\phi}\left(k_{r}\right) \approx 2 \pi M \frac{k_{0}^{2} L_{\varepsilon}}{k_{r}}\left[C^{2}(w)+S^{2}(w)\right] \Gamma_{n}\left(k_{r}\right),
$$

where $M$ is the value of $\left(n_{e} \partial \varepsilon / \partial n_{e}\right)^{2}$ near the reflecting layer. For propagation perpendicular to the magnetic field, $M=1$ for the ordinary mode, and $M=4$ for the extraordinary mode. This equation can be used for calculating the phase fluctuation of the reflected signal. Recent results from a series of experiments 7,9 in TFTR indicate that the main core of neutral beam heated plasmas is dominated by a broad band turbulence with a Gaussian power spectrum having a half-width $\Delta k_{r} \approx 1 \mathrm{~cm}^{-1}$ and a total density fluctuation $\left\langle\tilde{n}_{e} /\left.n_{e}\right|^{2}\right\rangle^{1 / 2} \approx 10^{-2}$. With this level of turbulence and $L_{\varepsilon} \approx 10 \mathrm{~cm}$, Eq. (5) gives $\left\langle|\tilde{\phi}|^{2}\right\rangle^{1 / 2} \approx 3.5 \mathrm{rad}$ for the $X$-mode with $k_{0}=25 \mathrm{~cm}^{-1}$. Moreover, by assuming $\left\langle\tilde{n}_{e} /\left.n_{e}\right|^{2}\right\rangle \propto\left(k_{r} L_{\varepsilon}\right)^{-2}$ (mixing length criterion), and $k_{r} \propto L_{\bar{\varepsilon}}^{-1}$ (Bohmscaling), Eq. (5) gives $\left\langle\tilde{\phi}^{2}\right\rangle^{1 / 2} \propto k_{\mathrm{o}} L_{\varepsilon}$. Hence, the effects of fluctuations in a tokamak fusion reactor will be much larger than in TFTR.

In single-channel reflectometry, the effects of fluctuations are reduced by averaging over a time window. Recently, a new type of reflectometer has been proposed 3,4 where two microwave beams with constant frequency separation $(\delta \omega)$ are simultaneously injected into the plasma, and the phase difference $\phi_{2}-\phi_{1}$ is measured while the frequencies are swept across a wide band. In comparison to the single channel reflectometer, this scheme offers the practical advantage of an easier phase tracking, since phase excursions are greatly reduced, as well as the possibility of minimizing Doppler effects. Phase fluctuations are compensated for by requiring that the radial separation $\delta$ of the two reflecting layers be such that $\left\langle\left\langle\tilde{\phi}_{2}-\left.\tilde{\phi}_{1}\right|^{2}\right\rangle^{1 / 2}<1\right.$. This condition, together with the assumption that the phase correlation function $\gamma(\delta) \equiv\left\langle\tilde{\phi}_{2} \tilde{\phi}_{1}\right\rangle /\left\langle\mid \tilde{\phi}^{2}\right\rangle$ is given by the Gaussian $\exp \left(-\delta^{2} / \Delta^{2}\right)$ (where $\Delta$ is the correlation length) gives 


$$
\frac{\delta}{\Delta}<\frac{1}{\left(2\left\langle\left.\tilde{\phi}\right|^{2}\right\rangle\right)^{1 / 2}} .
$$

From this, and the equation $\varepsilon\left(r_{c}\right)=0$ which gives $\delta / L_{\varepsilon} \approx 2 G \delta \omega / \omega$ (with $G=1$ for the ordinary mode and $G=1+\left(\omega / \omega_{p}\right)^{2}$ for the extraordinary mode), we obtain

$$
\frac{\delta \omega}{\omega}<\frac{\Delta}{2^{3 / 2} G L_{\varepsilon}}\left\langle|\tilde{\phi}|^{2}\right\rangle^{-1 / 2}
$$

For the TFTR tokamak with $\Delta \approx 2 \mathrm{~cm}, L_{\varepsilon} \approx 10 \mathrm{~cm},\left\langle|\tilde{\phi}|^{2}\right\rangle^{1 / 2} \approx 3.5$ and $G=7$, we get $\delta \omega / \omega<3 \times 10^{-3}$.

\section{B. Poloidal fluctuations}

In this section, we consider the effects of density fluctuations which vary along the poloidal direction. Indeed, it is well known that the ubiquitous broad band turbulence which exists in tokamaks has short scale lengths in any direction perpendicular to the magnetic field. To understand how this may affect reflectometry measurements in tokamaks, let us consider the simple case $^{7}$ where a one dimensional plasma equilibrium is perturbed by the density fluctuation $\tilde{n}_{e} / n_{e}=\delta n \cos \left(k_{r} r\right) \cos \left(k_{x} x\right)$. Here the orthogonal coordinates $(r, x)$ represent the radial and the poloidal direction of a tokamak, respectively. Near the reflecting region, the wave undergoes a phase modulation which, in the limit of geometric optics, is $\tilde{\phi}=\delta \phi \cos \left(k_{x} x\right)$, where $\delta \phi=\delta n k_{0}\left(\pi M L_{\varepsilon} / k_{r}\right)^{1 / 2}$ as given by Eq. (5) with $w>>1$. The Fourier expansion of the electromagnetic field $(\approx \exp (\tilde{i \phi}))$ near the cutoff contains the terms $J_{m}(\delta \phi) \exp \left(i m k_{x} x\right)$, where $J_{m}$ is the Bessel function of the first kind of order $m$. Of these components, those with $|m|<\left|k_{\alpha} / k_{x}\right|$ may propagate back to the receiver and contribute to the measured field. In reflectometry, the position of the reflecting layer is usually inferred from the phase of the $m=0$ component. This can be easily done in the case of $\delta \phi<<1$ where the spectrum of scattered waves is dominated by the $m=0$ component. On the other hand, as the level of turbulence increases and the value of $\delta \phi$ becomes greater than one, the largest components are those with $|m| \approx \delta \phi$. This results in a complicated interference pattern with large wave amplitude modulations. Correspondingly, the phase of the received wave exhibits large variations which are typical of any interference pattern. These conclusions are supported by results from a numerical solution of the wave equation ${ }^{7}$. Figure 1 shows the calculated spectrum of reflected waves in the vacuum region for the case of $k_{0}=25 \mathrm{~cm}^{-1}, X$-mode propagation, $k_{r}=k_{x}=1.0 \mathrm{~cm}^{-1}, \delta n=0.02$, and the plasma conditions of a typical TFTR discharge with a central density of $5 \times 10^{13} \mathrm{~cm}^{-3}$, and a toroidal 
magnetic field of $42.5 \mathrm{kG}$. These results are in good agreement with the Bessel-spectrum of geometric optics, as shown in Fig. 1. Figure 2 shows the amplitude contour plot of the interference pattern which is obtained by propagating the spectrum of Fig. 1 back in time in the absence of plasma. This contour plot, which is the image of the scattered field as it would appear to an observer in the vacuum region, shows everywhere large amplitude fluctuations with the exception of a narrow region near $r=273 \mathrm{~cm}$, the image plane. This is in agreement with the geometric optics approximation where the scattered field near the reflection point is $\approx \exp (\tilde{i \phi})$, i.e., the reflected wave has a constant amplitude. In Fig. 2, the image plane appears behind the cutoff plane because of the wave group delay. Figures 3 and 4 show the amplitude and phase of the reflected wave at the image plane and at the plasma boundary $(r=325)$, respectively. While at the image plane the amplitude is almost constant and the phase is proportional to the density fluctuation, at the plasma boundary the amplitude is strongly modulated and the phase exhibits large jumps. Moreover, even after removal of the jumps, which can be done only for a coherent fluctuation as that considered here, the phase is still very differen' from the density perturbation. Finally, as the value of $\delta n$ and/or that of $k_{x}$ increases, the region of small amplitude fluctuations narrows and disappears, and the agreement with geometric optics is lost. This example demonstrates how even a very simple density perturbation, as that considered here, can make the interpretation of reflectometry very problematic.

These conclusions apply to the case of turbulent fluctuations ${ }^{3,10}$, as well. For sufficiently large poloidal wavelengths and small turbulence levels, the effects of density fluctuations come predominantly from a region near the cutoff where the phase of the reflected wave is given by geometric optics (Eq. (3)), and the wave amplitude is nearly constant. For an observer in the vacuum region, the effects of plasma fluctuations appear to originate from a thin layer behind the cutoff, at an effective distance which is determined by the wave group velocity. After reflection, the statistical properties of the wave phase fluctuations are similar to those of density fluctuations near the reflecting region, and they can be derived from the latter by using the transfer function (5). In particular, the radial correlation length of the phase, considered as a function of $r_{c}$, is approximately equal to the radial scale of density fluctuations. Hence, if the full spectrum of reflected waves is collected with a lens, and an image of the cutoff is formed onto the plane of the receiver, the latter will sample an electromagnetic field with a nearly constant amplitude and a phase which, apart from a constant, is that of the probing wave after 
reflection. Under these conditions, the problem of averaging over phase fluctuations is similar to that discussed in the preceding section for the case of radial fluctuations. On the other hand, if instead the spectral components of the reflected wave are allowed to propagate freely to the receiver, as in standard methods of reflectometry, the measured phase fluctuation may not be given by Eq. (3) and, more importantly, its statistical properties may be completely different from those of turbulent fluctuations. This occurs when the phase of the reflected wave is strongly modulated $\left(\left\langle\left.\tilde{\phi}\right|^{2}\right\rangle^{1 / 2} \geq 2\right)$ by density fluctuations near the cutoff region, and the effective distance is larger than the diffraction length

$$
D \approx \frac{2 k_{0}}{\left\langle\tilde{\phi}^{2}\right\rangle k_{x}^{2}}
$$

where $k_{x}$ is the typical poloidal wavenumber of turbulent fluctuations. Equation (8) is obtained by imposing the condition that the spectral width $\Delta k_{r}=\left\langle|\tilde{\phi}|^{2}\right\rangle k_{x}^{2} / 2 k_{0}$ of the scattered waves satisfies the equation $D \Delta k_{r} \approx 1$. As an example, the values of $k_{0}=25 \mathrm{~cm}^{-1}, k_{x}=1.0 \mathrm{~cm}^{-1}$, and $\left\langle|\tilde{\phi}|^{2}\right\rangle^{1 / 2}=2$ give $D=12 \mathrm{~cm}$. When the first of the above conditions is satisfied (i.e., $\left\langle\tilde{\phi}^{2}\right\rangle^{1 / 2} \geq 2$ ), most of the electromagnetic energy is reflected away from the direction of specular reflection, and it is spread over an angle $\approx 2\left\langle|\tilde{\phi}|^{2}\right\rangle^{1 / 2} k_{x} / k_{0}$. Then, if the effective distance is larger than $D$, the receiver samples a complicated interference pattern with large amplitude fluctuations and random phase jumps. Under these conditions, it has been found, both experimentally and with numerical simulations ${ }^{10}$, that the correlation length of the measured phase becomes quickly much smaller than the radial scale of the turbulence, reaching values as small as a fraction of the free space wavelength. Moreover, the frequency $(f)$ spectrum of the measured phase tends towards a $1 / f^{2}$ dependence, irrespective of the spectrum of density fluctuations. This implies that the measured phase has a non stationary rms fluctuation level which increases with the time window of the measurement. The conclusion is that, when the phase of the reflected wave is strongly modulated by density fluctuations near the cutoff region and the receiver is located beyond the diffraction distance, the averaging of fluctuations becomes impossible, and standard reflectometry ceases to be a method for density measurements.

Ultimately, large levels of turbulent fluctuations will induce strong amplitude modulations of the scattered field everywhere, causing the complete failure of reflectometry. Since each spectral component of the reflected wave carries turbulence information from a region near its reflecting point, these amplitude modulations oscur when the turning points of the scattered waves are distributed over a distance $\Delta r_{c}$ which is comparable to the radial correlation length 
of turbulent fluctuations. To prevent this from happening, the condition $\Delta r_{c} / \Delta<\pi /\left(2\left\langle\mid \tilde{\phi}^{2}\right\rangle\right)^{1 / 2}$ must be satisfied. On the other hand, since $\Delta r_{c} / L_{\varepsilon} \approx\left\langle\left.\tilde{\phi}\right|^{2}\right\rangle k_{x}^{2} / k_{0}^{2}$, we obtain

$$
\left\langle|\tilde{\phi}|^{2}\right\rangle^{3 / 2}<2 \frac{\Delta}{L_{\varepsilon}} \frac{k_{0}^{2}}{k_{x}^{2}} .
$$

Again, for $k_{0}=25 \mathrm{~cm}^{-1}, k_{x}=1 \mathrm{~cm}^{-1}, \Delta \approx 2 \mathrm{~cm}$ and $L_{\varepsilon} \approx 10 \mathrm{~cm}$, we get $\left\langle\left.\tilde{\phi}\right|^{2}\right\rangle^{1 / 2}<6$. Equation (9) is the condition for the feasibility of density measurements with microwave reflectometry in tokamaks. It sets the limit for the applicability of Eq. (3) of geometric optics, as well.

\section{CONCLUSIONS}

In conclusion, we have shown that the major obstacle to the measurement of the density profile of tokamaks with microwave reflectometry is the strong modulation of the phase of the reflected wave which is induced by turbulent density fluctuations near the cutoff region. Plasma fluctuations which vary only along the radial direction, i.e., along the direction of wave propagation, cause a phase modulation of the reflected wave which can be compensated for with special averaging techniques. An example is the dual-frequency reflectometer ${ }^{3,4}$ where the averaging of fluctuations requires that the separation of the two reflecting layers satisfies the criterion (6). On the other hand, plasma fluctuations which vary along the poloidal direction, i.e., perpendicularly to the direction of wave propagation, may cause large modulations of the wave amplitude and random jumps of the measured phase. If the rms value of the phase

fluctuation is $\left\langle|\tilde{\phi}|^{2}\right\rangle^{1 / 2} \geq 2$, and the effective distance of the receiver is larger than the diffraction length $D$, averaging over fluctuations becomes very difficult and standard methods of reflectometry cannot be used for density measurements in tokamaks. Nevertheless, when the fluctuation level satisfies the condition (9), reflectometry measurements are still possible when the full spectrum of reflected waves is collected with a lens, and an image of the cutoff is formed onto the plane of a wide angle receiver

\section{ACKNOWLEDGMENT}

This work was supported by US Department of Energy Contract No. DE-AC02-76-CHO3073. 


\section{REFERENCES}

1J. Doane, E. Mazzucato, and G. Schmidt, Rev. Sci. Instrum. 52, 12 (1981).

${ }^{2}$ A. Cavallo, and R. Cano, Report EUR-CEA-FC 1137 (1982).

${ }^{3}$ G. Hanson, J. Wilgen, T. Bigelow, I. Collazo, and C. Thomas, Rev. Sci. Instrum. 63, 4658 (1992).

4J. Sanchez, B. Branas, T. Estrada, E. de la Luna, and V. Zhuravlev, Rev. Sci. Instrum. 63, 4654 (1992).

5E. Mazzucato, Bull. Am. Phys. Soc. 20, 1241 (1975).

6E. Mazzucato and R. Nazikian, Plasma Phys. Controlled Fusion 33, 261 (1991).

7E. Mazzucato and R. Nazikian, Phys. Rev. Lett. 71, 1840 (1993).

$8 \mathrm{M}$. Abramowitz and I. Stegun, Handbook of Mathematical Functions (Dover, New York, 1968).

${ }^{9}$ R. Fonck, G. Cosby, R. Durst, S. Paul, N. Bretz, S. Scott, E. Synakowski, and G. Taylor, Phys. Rev. Lett. 70, 3736 (1993).

10R. Nazikian and E. Mazzucato, these proceedings. 


\section{FIGURE CAPTIONS}

Fig. 1. Spectrum of reflected waves. Line is from the numerical solution of the wave equation; circles are from the geometric optics approximation.

Fig. 2. Amplitude contour plot of the interference pattern formed by the spectrum of waves of Fig. 1.

Fig. 3. Amplitude and phase of the reflected wave at the image plane $(r=273 \mathrm{~cm})$.

Fig. 4. Amplitude and phase of the reflected wave at the plasma boundary $(r=325 \mathrm{~cm})$. 


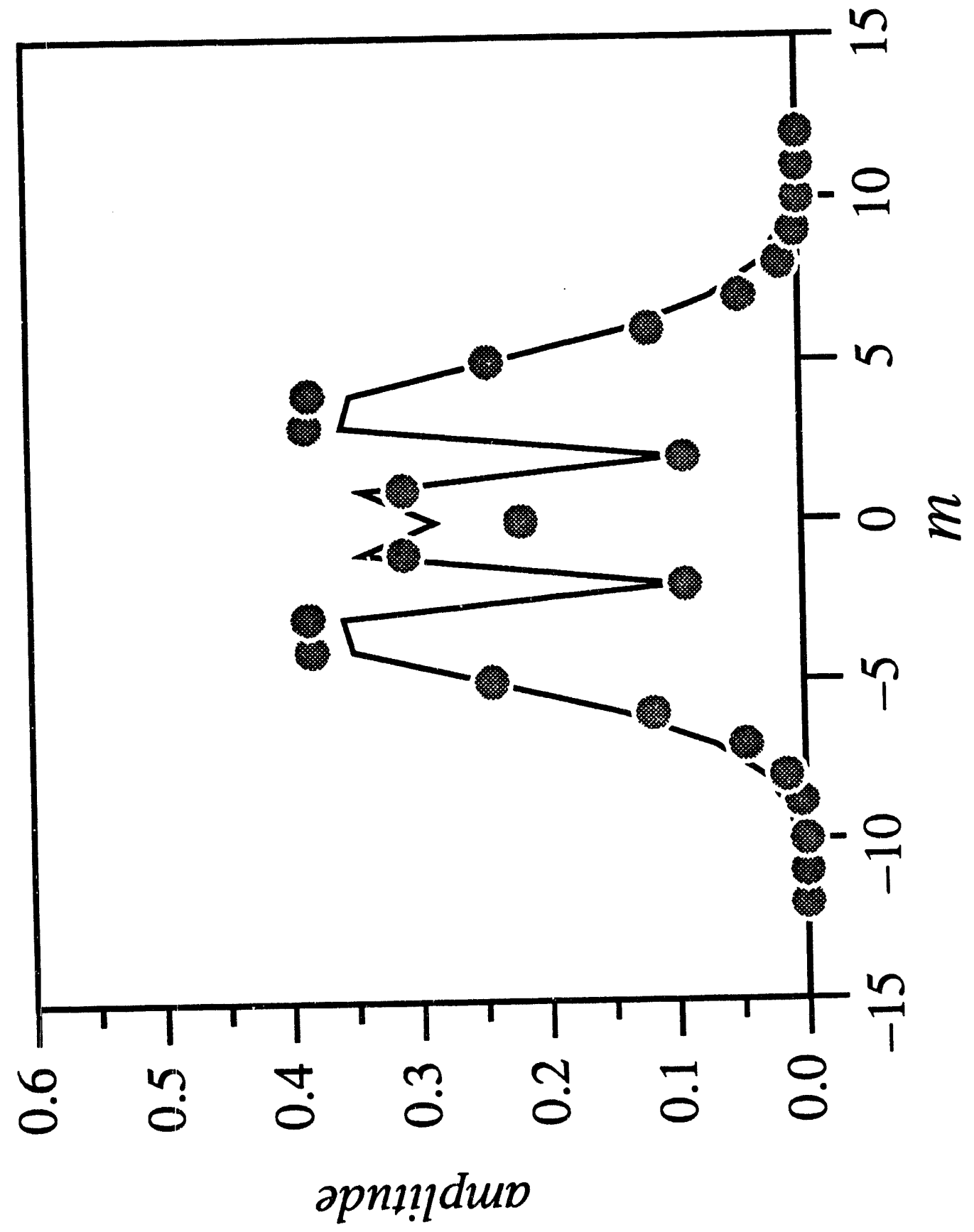

$\dot{0}$ 


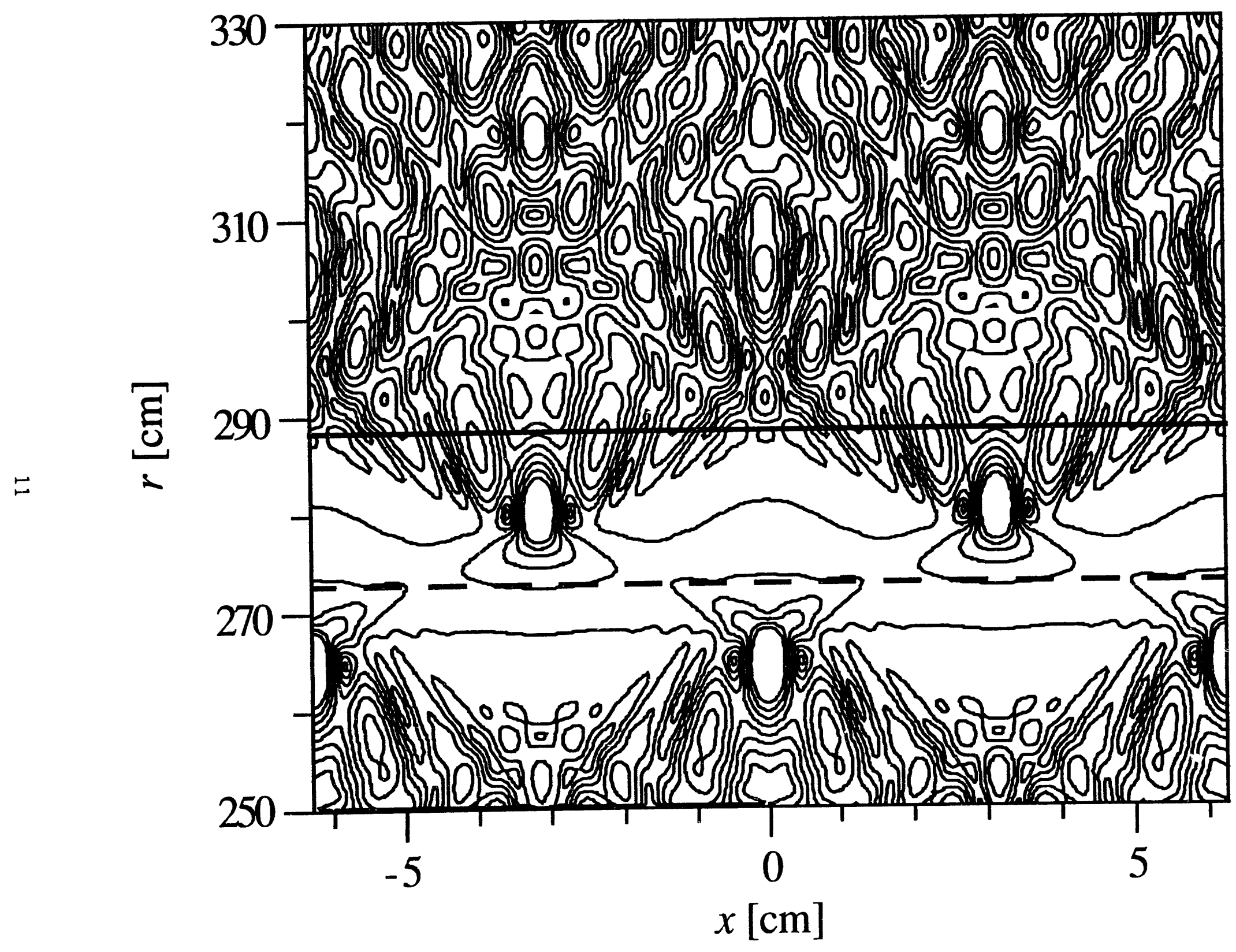

Fig. 2 


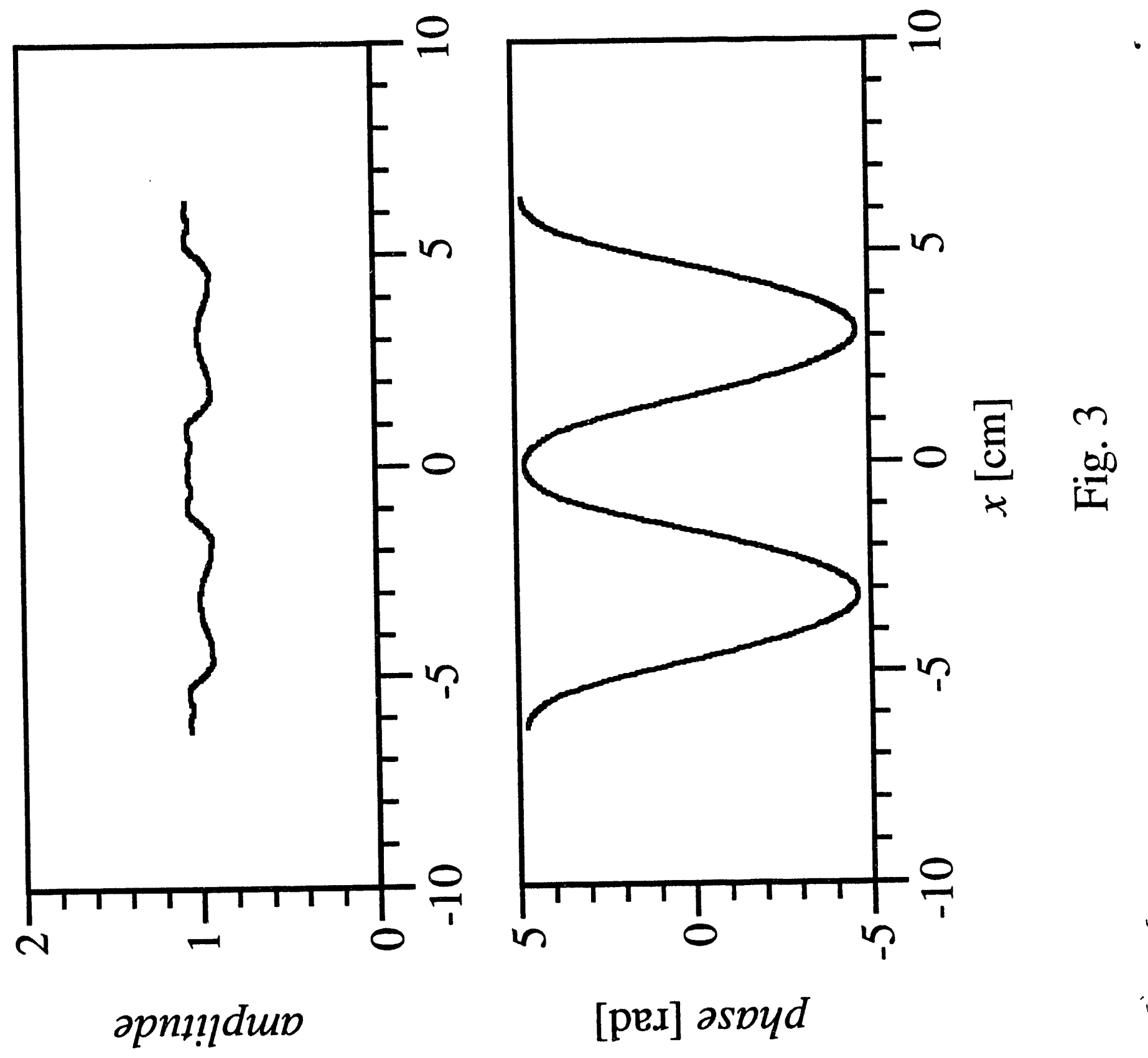



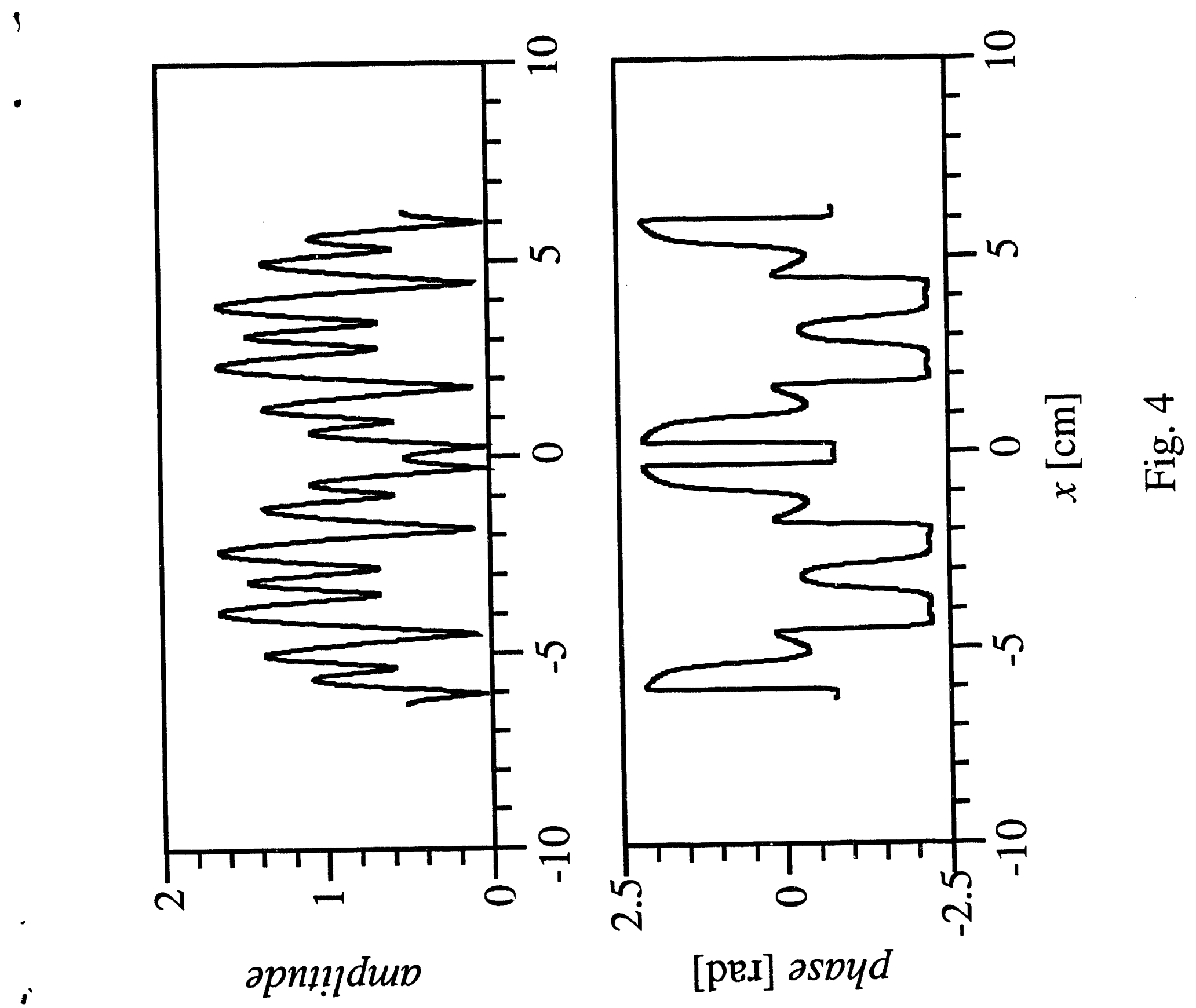


\section{EXTERNAL DISTRIBUTION IN ADDITION TO UC-420}

Dr. F. Paoloni, Univ. of Wollongong. AUSTRALIA

Prof. R.C. Cross, Univ. of Sydnoy, AUSTRALIA

Plasma Research Lab., Australian Nat. Univ., AUSTRALIA

Prof. I.R. Jones, Flinders Univ, AUSTRALIA

Prof. F. Cap, Inst. for Theoretical Physics, AUSTRIA

Prof. M. Heindler, Institut für Theoretische Physik, AUSTRIA

Prof. M. Goossens, Astronomisch Instituut, BELGIUM

Ecole Royale Militaire, Lab. de Phy. Plasmas, BELGIUM

Commission-European, DG. XII-Fusion Prog., BELGIUM

Prof. R. Boucique, Rijksuniversibit Gent, BELGIUM

Dr. P.H. Sakanaka, Instituto Fisica, BRAZIL

Prof. Dr. I.C. Nascimento, Instituto Fisica, Sao Paulo, BRAZIL Instituto Nacional De Pesquisas Espaciais-INPE, BRAZIL

Documents Office, Atomic Energy of Canada Lid., CANADA

Ms. M. Morin, CCFMTokamak de Varennes, CANADA

Dr. M.P. Bachynski, MPB Technologies, Inc., CANADA

Dr. H.M. Skarsgard, Univ. of Saskatchewan, CANADA

Prof. J. Toichmann, Univ. of Montreal, CANADA

Prof. S.R. Sreonivasan, Univ. cf Calgary, CANADA

Prof. R. Marchand, INRS-Energie et Materiaux, CANADA

Dr. R. Bolton, Centre canadien de fusion magnétique, CANADA

Dr. C.R. James, Univ. of Alberta, CANADA

Dr. P. Lukác, Komenského Universzita, CZECHO-SLOVAKIA

The Librarian, Culham Laboratory, ENGLAND

Library, R61, Rutherford Appleton Laboratory, ENGLAND

Mrs. S.A. Hutchinsen, JET Library, ENGLAND

Dr. S.C. Sharma, Univ. of South Pacific. FIJI ISLANDS

P. Măhonen, Univ. of Helsinki, FINLAND

Prof. M.N. Bussac, Ecole Polytechnique., FRANCE

C. Mouttet, Lab. de Physique des Milieux tonisés, FRANCE

J. Radet, CEN/CADARACHE - Bat 506, FRANCE

Prof. E. Economou, Univ. of Crete, GREECE

Ms. C. Rinni, Univ. of loannina, GREECE

Preprint Library, Hungarian Academy of Sci., HUNGARY

Dr. B. DasGupta, Saha Inst. of Nuclear Physics, INDIA

Dr. P. Kaw, Inst. for Plasma Research, INDIA

Dr. P. Rosenau, Israel Inst. of Technology, ISRAEL

Librarian, Intemational Center for Theo Physics, ITALY

Miss C. De Palo, Associazione EURATOM-ENEA, ITALY

Dr. G. Grosso, Istituto di Fisica del Plasma, ITALY

Prof. G. Rostangni, Istituto Gas lonizzati Del Cnr, ITALY
Dr. H. Yamato, Toshiba Res \& Devel Center, JAPAN

Prof. I. Kawakami, Hiroshima Univ., JAPAN

Prof. K. Nishikawa, Hiroshima Univ., JAPAN

Librarian, Naka Fusion Research Establishment, JAERI, JAPAN

Director, Japan Atomic Energy Research Inst., JAPAN

Prof. S. Itoh, Kyushu Univ., JAPAN

Research Info. Ctr., National Instit. for Fusion Science, JAPAN

Prof. S. Tanaka, Kyoto Univ., 'APAN

Library, Kyoto Univ., JAPAN

Prof. N. Inoue, Univ. of Tokyo, JAPAN

Secretary, Plasma Section, Electrotochnical Lab., JAPAN

Dr. O. Mitarai. Kumamoto Inst. of Technology, JAPAN

Dr. G.S. Lee, Korea Basic Sci. Ctr., KOREA

J. Hyeon-Sook, Korea Atomic Energy Research Inst., KOREA

D.I. Choi, The Korea Adv. Inst. of Sci. \& Tech., KOREA

Prof. B.S. Liley, Univ. of Waikato, NEW ZEALAND

Inst of Physics, Chinese Acad Sci PEOPLE'S REP. OF CHINA

Library, Inst. of Plasma Physics, PEOPLE'S REP. OF CHINA

Tsinghua Univ. Library, PEOPLE'S REPUBLIC OF CHINA

Z. Li, S.W. Inst Physias, PEOPLE'S REPUBLIC OF CHINA

Prof. J.A.C. Cabral, Instituto Superior Tecnico, PORTUGAL

Prof. M.A. Hellberg, Univ. of Natal, S. AFRICA

Prot. D.E. Kim, Pohang Inst. of Sci. \& Tech., SO. KOREA

Prof. C.I.E.M.A.T, Fusion Division Library, SPAIN

Dr. L. Stenflo, Univ. of UMEA, SWEDEN

Library, Royal Inst. of Technology, SWEDEN

Prof. H. Wilhelmson, Chalmers Univ. of Tech., SWEDEN

Centre Phys. Des Plasmas, Ecole Polytech. SWITzERLAND

Bibliotheok, Inst. Voor Plasma-Fysica, THE NETHERLANDS

Asst. Prof. Dr. S. Cakir, Middle East Tech. Univ., TURKEY

Dr. V.A. Glukhikh,Sci. Res. Inst. Electrophys.I Apparatus, USSR

Dr. D.D. Ryutov, Siberian Branch of Academy of Sci., USSR

Dr. G.A. Eliseev, I.V. Kurchatov Inst., USSR

Librarian, The Ukr.SSR Academy of Sciences, USSR

Dr. L.M. Kovrizhnykh, Inst. of General Physics, USSR

Kemforschungsanlage GmbH, Zentralbibliothek, W. GERMANY Bibliothek, Inst. Fur Plasmatorschung, W. GERMANY

Prof. K. Schindler, Ruhr-Universitát Bochum, W. GERMANY

Dr. F. Wagner, (ASDEX), Max-Planck-Institut, W. GERMANY

Librarian, Max-Planck-Institut, W. GERMANY 

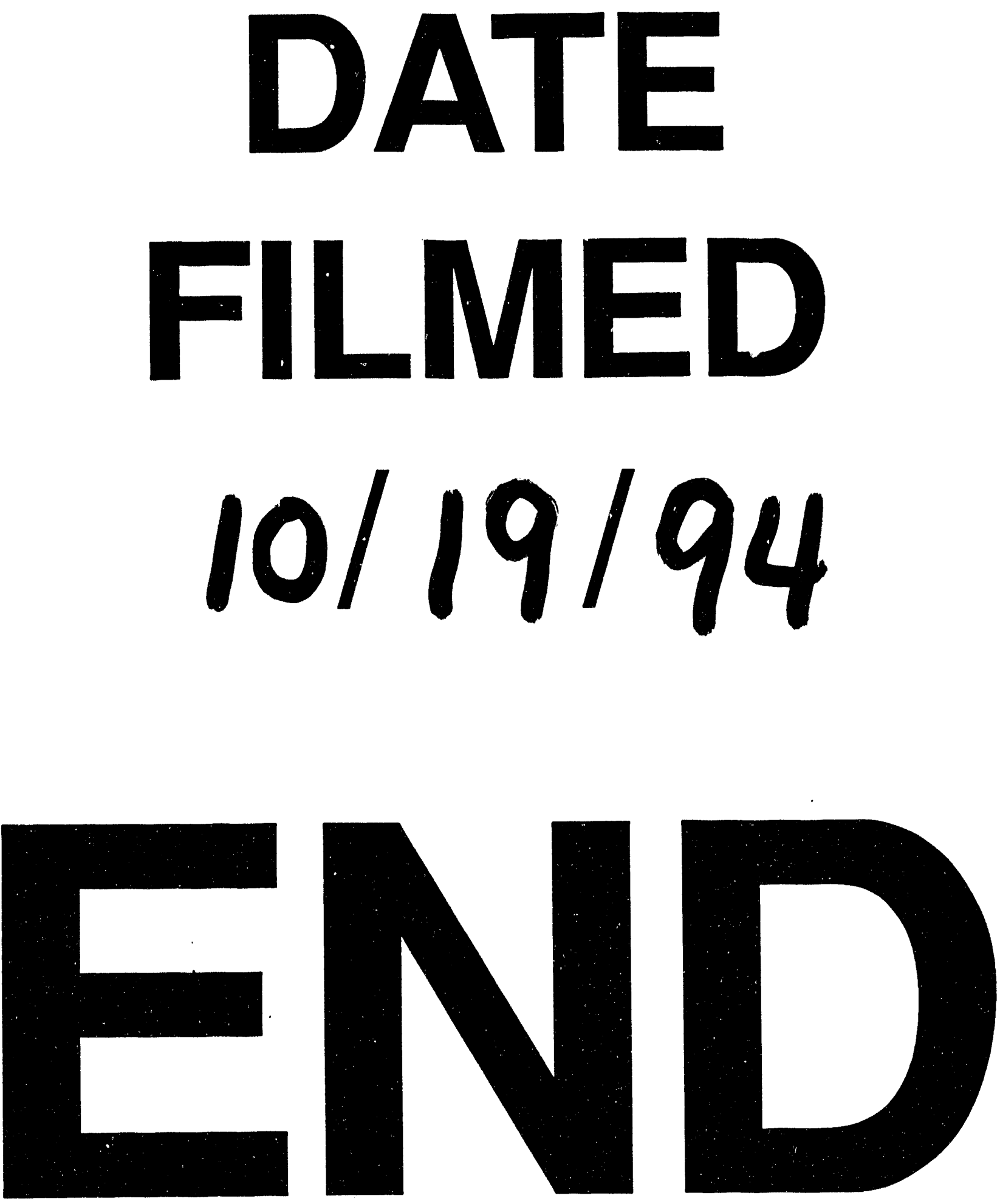
